\title{
La Vie romantique. Hommage à Loïc Chotard, colloque de la Sorbonne, textes réunis par André Guyaux et Sophie Marchal
}

\section{Lise Sabourin}

\section{(2) OpenEdition}

\section{Journals}

Édition électronique

URL : http://journals.openedition.org/studifrancesi/33317

DOI : 10.4000/studifrancesi.33317

ISSN : 2421-5856

Éditeur

Rosenberg \& Sellier

\section{Édition imprimée}

Date de publication : 1 décembre 2005

Pagination : 653-654

ISSN : 0039-2944

\section{Référence électronique}

Lise Sabourin, «La Vie romantique. Hommage à Loïc Chotard, colloque de la Sorbonne, textes réunis par André Guyaux et Sophie Marchal », Studi Francesi [En ligne], 147 (XLX | III) | 2005, mis en ligne le 30 novembre 2015, consulté le 19 avril 2021. URL : http://journals.openedition.org/studifrancesi/33317 ; DOI : https://doi.org/10.4000/studifrancesi.33317

Ce document a été généré automatiquement le 19 avril 2021.

\section{cc) $(9)$}

Studi Francesi è distribuita con Licenza Creative Commons Attribuzione - Non commerciale - Non opere derivate 4.0 Internazionale. 


\title{
La Vie romantique. Hommage à Lö̈c Chotard, colloque de la Sorbonne, textes réunis par André Guyaux et Sophie Marchal
}

\author{
Lise Sabourin
}

\section{RÉFÉRENCE}

AA. VV., La Vie romantique. Hommage à Loïc Chotard, colloque de la Sorbonne, textes réunis par André Guyaux et Sophie Marchal, Presses Universitaires de Paris-Sorbonne, 2003, pp. 592

Outre quelques articles hors de notre tranche séculaire (Paolo Tortonese, «Baudelaire et la philosophaillerie moderne», pp.483-522; Sophie Basch, «Le Cirque en 1869: les Hanlon-Lees dans la littérature», pp. 7-36; Jérôme Thélot, «Le Phénomène futur est une photographie» [sur Mallarmé], pp.461-474) ou correspondant à d'autres centres d'intérêt de Loïc Chotard (tel le rapport entre portrait, photographie et célébrité: Hélène DUFOUR, «Portraits du prochain siècle: un recueil de portraits littéraires en 1894», pp. 191-204; Claire BUSTARRET, «Dix portraits pour un anniversaire», pp. 107-142), cet important volume d'hommage au chercheur disparu à 38 ans concerne bien des auteurs et des problématiques de l'époque romantique à l'étude de laquelle il a tant œuvré.

tre une communication consacrée à l'analyse d'«un procédé de style commun à Chateaubriand et à Proust» la présentation de l'effet avant la cause, ce "côté Dostoïevski de Mme de Sévigné» (Piero TOFfano, pp. 475-482), le monde des balzaciens auquel appartenait Loïc Chotard lui rend hommage. Roger PIERROT (pp. 409-416) apporte quelques compléments à son Ève de Balzac à propos de la famille Rzewuski. Stéphane VACHON (pp. 523-538) explore le «miroir concentrique» (archétypalement énoncé dans La Peau de chagrin), révélateur de la tension de l'œuvre entre «miroir du monde» et 
«âme concentrique» du créateur. Patrick BERTHIER (pp.37-48) met en corrélation Marsay, tout chargé d'énergie, et le suicidaire Rolla de Musset, deux figures de refus symétriques de «l'infini devenu palpable» (La Fille aux yeux d'or). Arlette MICHEL, rappelant l'édition de Murger par Chotard, étudie «la vie de bohème» chez Balzac (pp. 363-372): outre Un Prince de la bohème, Illusions perdues, Z. Marcas, La Muse du département la situent aux antipodes de Nodier, car brisée dans son élan poétique au lieu de le nourrir. Frank LESTRINGANT établit «une généalogie de la grisette» (pp. 321-336), de la Manon de Prévost, par Beaumarchais, jusqu'aux modernes figures «vulgaires» de la libertine chez Murger et Musset.

3 L'histoire littéraire, on le sait, a formé l'érudit qu'était le dédicataire. Fabrice wiLHLEM (pp. 539-554) invite à rénover la question biographique en littérature en cherchant à atteindre «la vie par l'oeuvre qui en dévoile la réalité psychique» à propos de La Vénus d'Ille, en y sondant «la fantaisie de meurtre» comme libération des pulsions par la fiction. Sarga moussa discerne l'impact de la mort de «Julia dans le Voyage en Orient de Lamartine» (pp. 389-398): «figure tragique de la destinée humaine», sa fille est aussi «auto-représentation du moi-voyageur» et axe de «littérarisation du genre». MarieRenée MoRin (pp.373-388) démontre comment le cheval tient grande place dans la relation du voyageur Lamartine à la nature, mais aussi dans son regard sur le monde et son sens de l'action. Antoine COMPAGNON (Pp. 169-178) nous propose de "courir, dépister, relancer, traquer dans Angélique» de Nerval la métaphore de la chasse, dont le va-et-vient entre Valois et bibliothèque, archives et librairie est emblématique de la quête du chercheur. Jean-Marc HOVASSE (pp. 249-276) explique la rareté des publications hugoliennes dans la Revue des deux mondes (1831-1865): outre sa méfiance envers les publications pré-originales, le poète trahit ainsi sa préférence pour des journaux animés par des proches avant d'utiliser la grande revue à des fins publicitaires et idéologiques après l'exil.

4 Loïc Chotard était l'âme de la publication de la Correspondance de Vigny: Nathalie PREISS (pp. 417-418) retrace brièvement sa plongée aventureuse et jubilatoire «tout au fond» des archives Sangnier qui en nourrissent la réédition très enrichie. Thierry BoDIN (pp. 49-72) publie des extraits du «Carnet Bunbury» à paraître, qui témoignent du combat dévoué mené par Vigny dans l'écheveau de la succession de son beau-père anglais, parallèlement aux batailles sur la propriété littéraire et lors de l'élection académique, mais aussi à la gestation des Destinées.

5 La dernière grande entreprise du brillant chercheur fut le commissariat de l'exposition Vigny et les arts, lors du bicentenaire de 1997. Le théâtre tient donc sa place au sein des Muses du Parnasse. Barry DANIELs étudie «La Venise de Vigny, du More au Marchand» (pp. 179-190): mélancolique et voluptueuse, la ville nécessita pour sa mise en scène des tractations importantes dans l'évolution dramatique, son décor s'harmonisant à la naissance de la liaison entre Vigny et Marie Dorval avant d'incarner la rupture entre Musset et Sand. Sophie MARCHAL juge révélatrice de la complexité du romantisme des années 1820 l'ambiguë relation, entre romantiques et classiques, de «Victor Hugo et Jacques Ancelot, de la scène dramatique à l'Académie» (pp. 337-362). Gianni IOTTI, dans «les métamorphoses de Triboulet» (pp. 277-292), voit la monstruosité comme «coexistence de composantes [morales] que le drame rend incompatibles» (p. 277), tout en en révélant dualité et puissance d'autodestruction.

6 Dans le domaine pictural, Stéphane GUÉGAN (pp.221-238) confirme le désir de nouveauté, constitutif du romantisme, chez Girodet, non seulement dans ses relations 
avec Vigny, mais aussi Stendhal qui loue, à l'inverse de Guizot, son tableau sur La Révolte du Caire au Salon de 1810. Lise SABOURIN (pp. 419-436) confronte des œuvres de Jules Ziegler, Maurice Denis et Raphaël Drouart sur Eloa pour comprendre les raisons de leur choix, leur parti pris d'artistes et l'apport que leur illustration donne à la lecture du poème de Vigny. Bruno CHENIQUe (pp. 143-168) rapproche quelques «stratégies de résistance» excentriques de Géricault avec le dandysme littéraire des romantiques. Christiane Peltre (pp.399-408) montre Chassériau à l'écart des préoccupations de modernité des "poètes de ces derniers temps“», selon l'expression d'Ingres, mais participant du romantisme à la manière de Maurice de Guérin et préparant l'univers baudelairien. Barbara WRIGHT (pp. 555-564) démontre en quoi «le héros romantique de la Franche-Comté», Julien Sorel, est à mettre en parallèle avec l'entreprise de Courbet de «libérer la création des contraintes de sa forme et de son support» dans une «préoccupation de réflexivité» pré-freudienne.

7 En musique, Catherine GAVIGLIO-FAIVRE D'ARCIER se lance «à la recherche d'une collection perdue, la bibliothèque musicale de Lovenjoul» (pp. 205-220): les parcelles actuellement décelables montrent un intérêt pour la soprano Marie Cabel et une appréciation relativement conformiste des opéras du temps qui font s'interroger sur l'importance et le devenir de ces archives. Hervé LACOMBE (pp.309-320) recense les sept poèmes hugoliens mis en musique par Bizet et confronte ses adaptations avec le texte d'Adieux de l'hôtesse arabe et d'Après l'Hiver, révélant ainsi une paternité spirituelle profonde. Emilio SALA, «autour d'une chanson savoyarde» (pp.437-454), prouve que ce genre concilie le «romantisme populaire» et l'«imagination mélodramatique» propre à la première moitié du XIX siècle. André JARRY (pp. 293-308) enquête sur deux autres émigrés de cette province à Paris, les frères Challamel: Pierre-Joseph, le catholique graveur et éditeur romantique de la France littéraire; Augustin le cadet, historien républicain et anticlérical.

8 Ce volume se devait de proposer quelques synthèses sur le romantisme. Michel BRIX (pp.93-106) tente de percer, à travers les définitions données par Chateaubriand, Senancour et Sand, puis sa perception par Baudelaire et Flaubert, la filiation entre «mal du siècle et bovarysme». André GUYAUX voit dans «La "pâleur verte“ du lendemain» (pp. 239-247) un motif symbolique, de Stendhal, Musset et Nerval à Baudelaire, Flaubert et Rimbaud, du «réveil difficile après un siècle libertin» qu'a manifesté le XIX ${ }^{e}$. Frank Paul BOWMAN (pp. 73-92), après cinquante années de réflexion sur «Les caractères du romantisme français», considère qu'une approche dualiste constitue un dépassement de ses contradictions apparentes: «exotisme et retour à la tradition nationale, innovation dans les formes et recherche des contraintes formelles, culte de la nature et culte de la ville, pessimisme et croyance au progrès, irrationalisme et quête d'un système rationaliste universel» (p. 73). Quête en pleine lucidité et goût fasciné des abysses qui caractérisent bien les qualités de romantique renouvelé que fut Loïc Chotard en notre siècle! 